\title{
Gall bladder sludge formation during prolonged fasting after gastrointestinal tract surgery
}

\author{
L BOLONDI, S GAIANI, S TESTA, AND G LABÒ \\ From the I Clinica Medica, Università di Bologna, Bologna, Italy
}

SUMmARY In this study we have ultrasonographically assessed the prevalence of sludge in a group of 48 fasting patients after gastrointestinal tract surgery. Ultrasound examinations were carried out daily in each patient, beginning on the day before surgery. The period of fasting lasted from seven to 10 days. The presence of sludge was demonstrated within the seventh day in seven out of the 48 patients. In 38 cases fast lasted for a further three days. The total number of sludge-positive patients after 10 days was 12 out of 38 . Ultrasound controls were performed after six and 12-24 month interval and showed the presence of gall stones with different ultrasonographic patterns in three sludge positive patients. We conclude that in the early postoperative period there is a high risk for sludge development and that in some cases sludge may subsequently evolve into gall stones.

Very recent papers ${ }^{12}$ have reported a high frequency of gall bladder disease in patients on long-term parenteral nutrition (TPN). In particular, the presence of gall bladder sludge is strictly related to the duration of TPN and it may result in eventual gall stone formation. ${ }^{2}$ The enhanced risk of gall bladder disease in these patients has been ascribed to bowel rest and gall bladder stasis.

In 1981 we decided to undertake a prospective study using sequential ultrasound examinations to assess the prevalence of gall bladder sludge and lithiasis in patients submitted to prolonged fasting after gastrointestinal surgery. This clinical condition is similar to TPN in that there is an absence of oral feeding, but the composition of the intravenously administered fluids is substantially different. The absence of a meaningful caloric intake and prior anaesthesia and abdominal surgery make this group of patients distinctive.

\section{Methods \\ PATIENTS \\ To study the effect of prolonged fasting on the formation of biliary sludge, we selected a group of \\ Address for correspondence: Dr Luigi Bolondi, I Clinica Medica, Policlinico S Orsola, 40138 Bologna, Italy. \\ Received for publication 3 August 1984}

patients who were about to undergo gastrointestinal surgery.

Conditions necessary for admission to this prospective study were: (1) absence of gall bladder disease, as assessed by a previous ultrasonographic study; (2) no laboratory alterations in liver function tests (GOT, GPT, alkaline phosphatase, gamma-glutamil-transpeptidase); (3) no administration of opiates or anticholinergic drugs either before operation or in the early postoperative period.

A total of 48 patients (23 men, 25 women; aged $32-83$ years, mean $62 \cdot 6 \pm 13 \cdot 3$ years) were examined. Mild diabetes was detected before the operation in 10 out of 48 patients. None of them was treated with insulin. Abnormal rises in serum cholesterol and/or triglycerides were found in 13 patients. Nineteen of these patients had an upper gastrointestinal tract operation (16 partial gastrectomy, three total gastrectomy) and 29 were operated on the lower gastrointestinal tract (two colonic resection, seven right emicolectomy, nine left emicolectomy, 11 amputations of the rectum). The final diagnosis of each patient is reported in Table 1.

The period of fasting began the day before the operation and lasted for at least seven days. In 38 of the patients fasting continued for 10 days. In all patients the following amount of intravenous fluids were administered daily for the total fasting period: glucose $5 \%$ solution, $500 \mathrm{ml}$; fructose $5 \%$ solution, 
Table 1 Final diagnosis in patients admitted to the study

\begin{tabular}{lc}
\hline Diagnosis & $\begin{array}{l}\text { Patients } \\
\text { (no) }\end{array}$ \\
\hline Gastric or duodenal ulcer & 6 \\
Gastric carcinoma & 13 \\
Colonic polyposis & 2 \\
Colonic neoplasm & 16 \\
Neoplasm of the rectum & 11 \\
Total & 48 \\
\hline
\end{tabular}

$1000 \mathrm{ml}$; electrolyte solution, (sodium chloride $3 \mathrm{~g}$, calcium chloride $0 \cdot 1 \mathrm{~g}$, potassium chloride $0 \cdot 15 \mathrm{~g}$, sodium lactate $1.15 \mathrm{~g}$, in $500 \mathrm{ml}$ ), $1000 \mathrm{ml}$, for a total input of $300 \mathrm{cal} / \mathrm{day} ; 300 \mathrm{ml}$ of plasma were administered every two days.

\section{ULTRASOUND STUDY OF THE GALL BLADDER}

Ultrasound examination was always carried out at the patients' bedside using a high resolution realtime scanner with a $3.5 \mathrm{MHz}$ linear array transducer. In all cases the examinations began the day before surgery (after overnight fasting) and were sequentially carried out every day in the early morning during the fasting period and for at least five days after oral refeeding was started. Ultrasonography was also repeated after a six month interval in all patients in whom gall bladder sludge was observed.

A further ultrasonographic control was performed in 28 of the 48 patients after a $12-24$ month interval. The remaining 20 patients dropped out of the study.
STATISTICAL ANALYSIS

To identify factors other than the duration of the fast that might influence the formation of sludge, we used $\chi^{2}$ analysis to compare the rate of sludge formation in the following subgroups: (a) men and women; (b) patients with upper and lower gastrointestinal tract operations; (c) diabetic and nondiabetic patients; (d) normal and abnormal serum triglycerides and cholesterol. Using Student's $t$ test, we also compared age and duration of anaesthesia in sludge-negative and sludge-positive patients.

\section{Results}

The presence of gall bladder sludge was shown within the seventh day in seven of the 48 patients $(14.5 \%)$. Six of the patients with sludge and 32 without sludge remained fasting for a further three days. Between the seventh and the 10th day sludge developed in another six patients among the 32 who had been negative during the first period of study (Fig. 1). Therefore, the total number of sludgepositive patients after 10 days of fasting was 12 out of $38(31.6 \%)$.

After oral refeeding the quantity of sludge within the gall bladder lumen tended to decrease, but complete disappearance was observed in only three patients after five days of oral refeeding.

The 13 sludge-positive patients were reexamined after six months and highly echogenic foci, interpreted as gall stones, were found in three cases, the remaining 10 showing completely normal gall bladders. These patients were asymptomatic and no
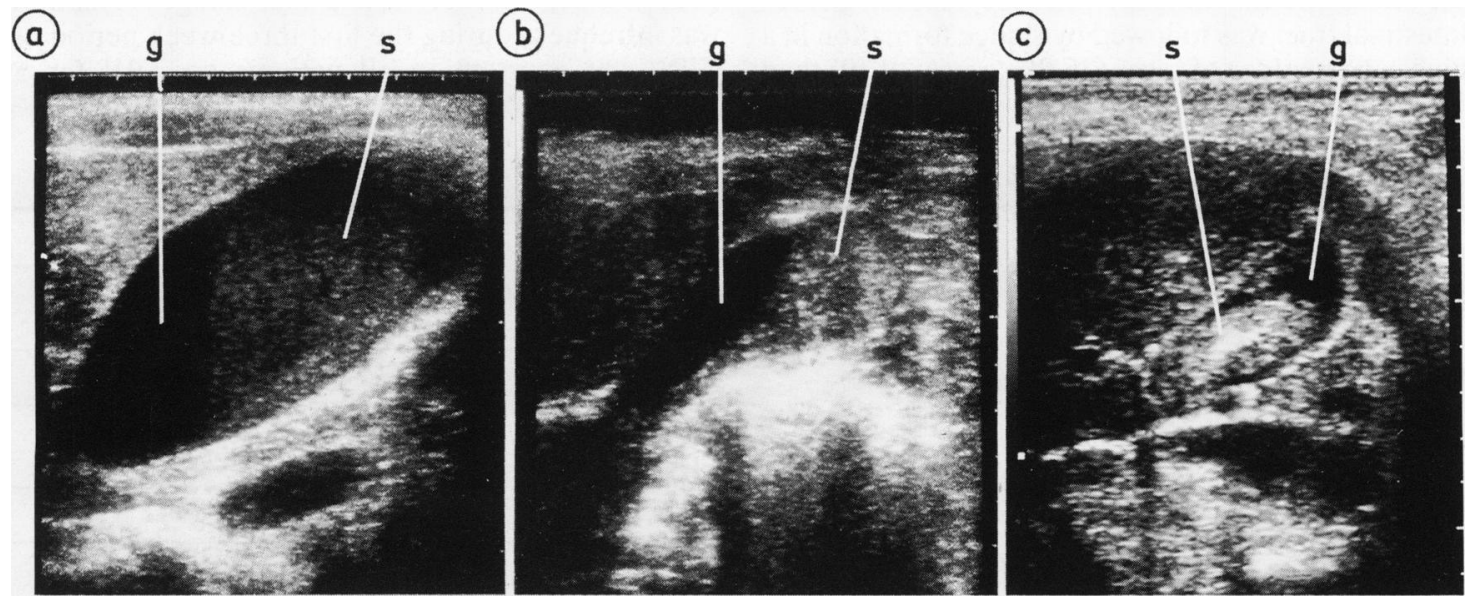

Fig. 1 Different aspects of gall bladder sludge at ultrasound examination. Oblique intercostal scans. (a) The sludge appears as fine low level echoes. (b) and (c) Sludge is more compact and shows a higher echogenicity. Gall bladder=g; sludge $=s$. 
alterations of the gall bladder wall suggestive of cholecystitis were seen at ultrasonography. In one case sharp acoustic shadows were present behind the echogenic foci while in the other two cases the shadows were less or not evident (Fig. 2).

Ultrasound controls was performed after a 12-24 month interval in 28 out of the 48 patients. Eighteen of these patients had been sludge-negative and 10 sludge-positive in the early postoperative period. Two patients of this group had been found to have gall stones at the six month control while the third patient had died from metastatic involvement of the liver.

This control revealed gall stones in only two patients in whom they had previously been shown.

In certain cases, the formation of sludge was associated with some abnormal physical or laboratory characteristics (Table 2). In relation to the sex of the patients, the prevalence of sludge was higher in women (36\%; nine of 25$)$ than in men $(17.4 \%$; four of 23), but this difference, analysed by $\chi^{2}$ method, was not significant. No difference was found, using Student's $t$ test, in the mean $( \pm S D)$ age of sludge-positive $(64 \cdot 3 \pm 9 \cdot 2)$ and sludge-negative patients $(61 \cdot 6 \pm 14 \cdot 6)$.

Sludge formation was similar in diabetic $(30 \%$; three of 10$)$ and non-diabetic patients $(26.3 \% ; 10$ of 38 ). On the contrary, a higher prevalence of sludge was found in patients with serum cholesterol and/or triglyceride alterations (38.5\%; five of 13$)$ than in normal patients $(22.9 \%$; eight of 35$)$, but this difference was not significant using the $\chi^{2}$ method. The other major factor which may influence the formation of sludge in our group of patients could be related to the type of operation and the duration of the anaesthesia. Surgery on the upper gastrointestinal tract was followed by sludge formation in a higher percentage of cases $(36.8 \%$; seven of 19$)$ than

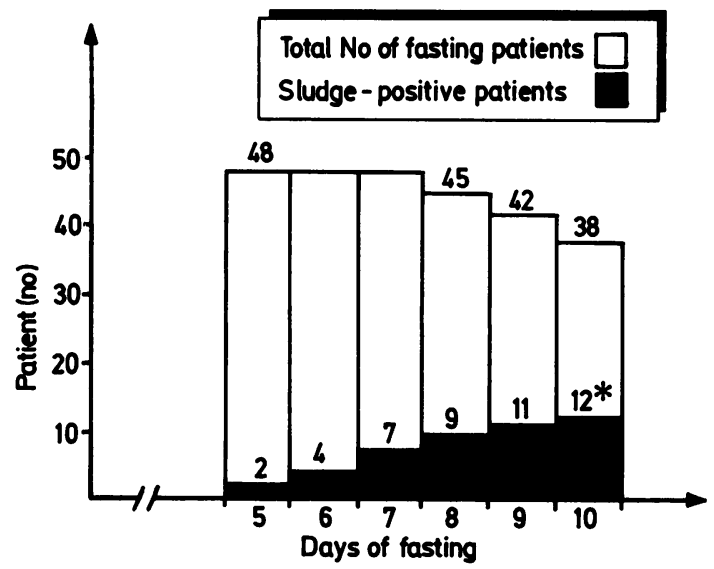

Fig. 2 Gall bladder sludge formation in relation to the period of fasting. * Another sludge-positive patient began oral refeeding on the seventh day and therefore is not included in the group of fasting patients on the 10th day.

lower gastrointestinal tract surgery $(20.6 \%$; six of 29 ), the difference not being significant using the $\chi^{2}$ method. The duration of the anaesthesia did not significantly influence sludge formation (Table 2).

\section{Discussion}

This prospective study provides valuable evidence of the relationship between prolonged fasting and gall bladder sludge formation in a group of patients who underwent gastrointestinal surgery.

A similar findings has been described by Messing et $a l^{2}$ during prolonged total parenteral nutrition (TPN). These authors found that sludge formation was infrequent during the first three-week period of TPN, but constant in all patients on TPN for a

Table 2 Relationship between the presence of sludge and patients' profile

\begin{tabular}{|c|c|c|c|}
\hline & & Sludge positive & Sludge negative \\
\hline Sex & $\begin{array}{l}\text { Male } \\
\text { Female }\end{array}$ & $\begin{array}{ll}4 / 23 & (17.4 \%) \\
9 / 25 & (36 \%)\end{array}$ & $\begin{array}{l}19 / 23(82 \cdot 6 \%) \\
16 / 25(64 \%)\end{array}$ \\
\hline Age mean $\pm S D$ (years) & & $64 \cdot 3 \pm 9 \cdot 2$ & $61 \cdot 6 \pm 14 \cdot 6$ \\
\hline GI tract surgery & $\begin{array}{l}\text { Upper } \\
\text { Lower }\end{array}$ & $\begin{array}{l}7 / 19(36 \cdot 8 \%) \\
6 / 29(20 \cdot 6 \%)\end{array}$ & $\begin{array}{l}12 / 19(63 \cdot 2 \%) \\
23 / 29(79 \cdot 4 \%)\end{array}$ \\
\hline Duration of anaesthesia mean $\pm S D(\min )$ & & $158 \pm 53 \cdot 6$ & $147 \cdot 3 \pm 56 \cdot 2$ \\
\hline Diabetes & $\begin{array}{l}\text { Present } \\
\text { Absent }\end{array}$ & $\begin{aligned} 3 / 10 & (30 \%) \\
10 / 38 & (26 \cdot 3 \%)\end{aligned}$ & $\begin{array}{c}7 / 10(70 \%) \\
28 / 38(73 \cdot 7 \%)\end{array}$ \\
\hline Serum cholesterol and/or trygliceride alterations & $\begin{array}{l}\text { Present } \\
\text { Absent }\end{array}$ & $\begin{array}{l}5 / 13(38.5 \%) \\
8 / 35(22.9 \%)\end{array}$ & $\begin{array}{r}8 / 13(61 \cdot 5 \%) \\
27 / 35(77 \cdot 1 \%)\end{array}$ \\
\hline
\end{tabular}


period over six weeks. In that study, sonograms taken on the 12th day \pm two days (mean \pm SEM) did not show evidence of sludge in any patient. On the contrary, in our group of patients daily ultrasound examinations detected sludge in seven out of 48 cases $(14.5 \%)$ after only seven days of fasting. As shown for the duration of TPN, the period of fasting play a fundamental role in the development of sludge. Six patients, who were sludge-negative during the first period, became sludge-positive between the seventh and tenth days of fasting.

As hypothesised for TPN, we believe that sludge formation is essentially induced by gall bladder hypotonicity and stasis after suppression of oral food intake. The period of time necessary for sludge formation, however, is significantly lower in our group of patients than in TPN. This may be explained by taking into account that factors other than the suppression of meal induced contractility are involved. Gall bladder hypotonicity may be enhanced by the paralytic effect of abdominal surgery and anaesthesia. In addition, it is known that dilatation of the gall bladder occurs in the late postoperative period after elective gastric surgery, ${ }^{3}$ presumably because of inadvertent sectioning of the hepatic branch of the vagus nerve. ${ }^{4}$

The influence of fasting on the composition of hepatic ${ }^{5}$ and gall bladder ${ }^{6}$ bile in humans has already been studied for a period of 10-20 hours: gall bladder bile is significantly supersaturated after 15 hours, but cholesterol saturation falls after 20 hours of fasting. ${ }^{6}$ No data are available on gall bladder bile modifications for a period of fasting as long as we have studied.
In our group of patients, sludge formation may also be favoured by bile stratification and sedimentation of its components as shown by $\mathrm{Tera}^{7}$ in in vivo and in vitro studies. Ultrasonographic findings are in agreement with this hypothesis because sludge appears as a collection of fine echoes lying in the most dependent part of the gall bladder and with a lower intensity than those produced by gall stones. It has been experimentally shown ${ }^{8}$ that highly viscous desiccated bile appears echogenic, and it is commonly accepted that biliary sludge is essentially thick bile. In vitro studies suggest that the echoes of biliary sludge originate from pigment granules ${ }^{9}$ or cholesterol crystals. ${ }^{10}$

As sludge did not develop in all patients fasting for seven-10 days, we investigated some other factors which may influence sludge formation. The higher trends of sludge formation in women and in type IIb hyperlipoproteinemic patients are probably because of the same mechanism which induces a higher prevalence of gall stones in these patients; ${ }^{11}$ upper gastrointestinal tract surgery might cause more significant gall bladder hypotonicity than lower gastrointestinal tract surgery through an accidental vagal injury.

The follow up of the sludge-positive patients, after oral refeeding was initiated, showed that the disappearance of the sludge was not immediate. This datum is in agreement with the findings of Messing $^{2}$ in TPN patients. Echogenic foci interpreted as stones (Fig. 3) were seen within the gall bladder of three sludge-positive patients six months after surgery and were confirmed in two of these patients examined after a 12-24 month interval. In
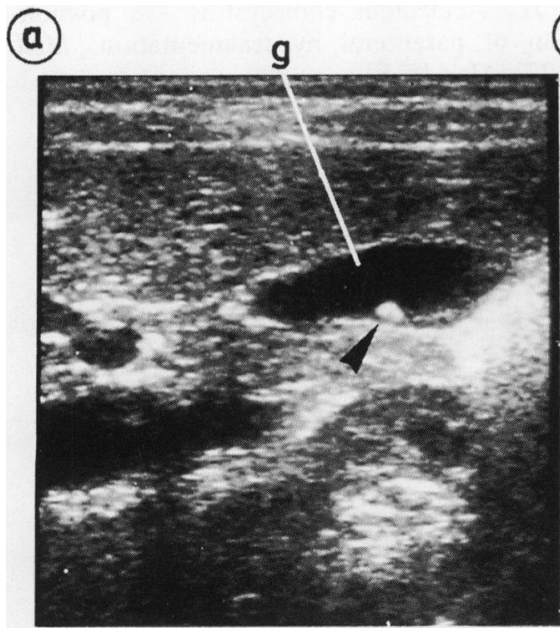
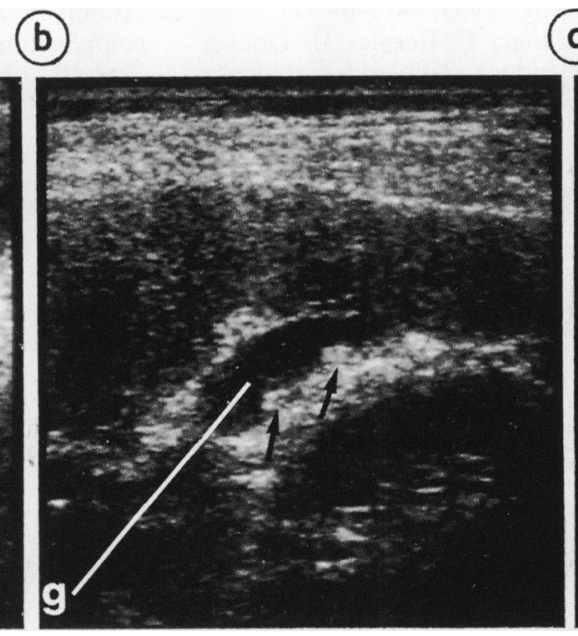
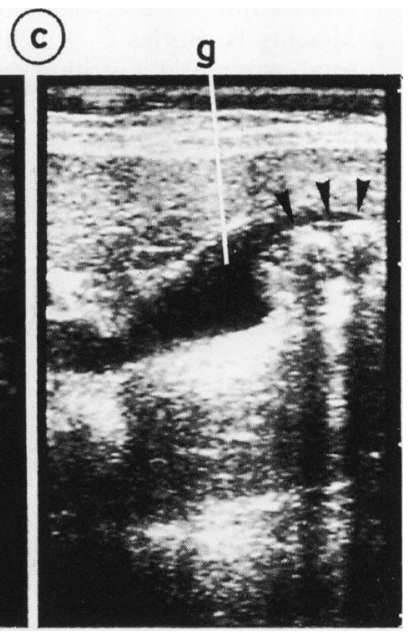

Fig. 3 (a), (b) and (c): ultrasonographic appearance of gall stones (arrows) occurring in our group of patients.

Parasagittal scans. In (c) stones are mixed with sludge. Gall bladder $=g$. 
two cases, however, the ultrasound patterns of stones was not typical, as acoustic shadows were not displayed behind the stones. These findings are very similar to those described by Britten et $\mathbf{l l}^{12}$ as 'sludge balls' and may represent an early evolutive stage of gall stones.

The finding of stones in only three cases out of 13 sludge-positive patients shows that supersatured bile and sludge occurring during prolonged fasting, are a necessary, but not a sufficient, cause for gall stones formation. Differences in cholesterol crystal formation (nucleation time) $)^{1314}$ may explain why stones developed only in some patients and not in others.

The occurrence of acute acalculous cholecystitis is reported in patients undergoing prolonged TPN. ${ }^{1}{ }^{15}$ This event was never observed in our group of fasting patients after surgery. It is possible that a longer period of gall bladder stasis, or the contribution of other factors, is necessary for the occurrence of acute acalculous cholecystitis.

In conclusion this study supports the hypothesis that the prolonged suppression of oral food intake in patients operated on the gastrointestinal tract, resulting in absence of meal stimulated gall bladder contraction, may be an important prerequisite to sludge development in this group of patients.

We are grateful to Mrs Ann Collins for revising the English language.

\section{References}

1 Roslyn JJ, Pitt HA, Mann LL, Ament ME, Den Besten L. Gallbladder disease in patients on long-term parenteral nutrition. Gastroenterology 1983; 84: 148-54.

2 Messing B, Bories C, Kustlinger F, Bernier JJ. Does total parenteral nutrition induce gallbladder sludge formation and lithiasis? Gastroenterology 1983; 84: 1012-9.

3 Cox HT, Doherty" JF, Kerr DF. Changes in the gallbladder after elective gastric surgery. Lancet 1958; 1: 764-6.

4 La Morte WW, Schoetz DJ, Jr., Birkett DH, Williams LF, Jr. The role of the gallbladder in the pathogenesis of cholesterol gallstones. Gastroenterology 1979; 77: 580-92.

5 Metzger AL, Adler R, Heymsfield S, Grundy SM. Diurnal variation in biliary lipid composition. $N$ Engl $J$ Med 1973; 288: 333-6.

6 Bloch HM, Thornton JR, Heaton KW. Effects of fasting on the composition of gallbladder bile. Gut 1980; 21: 1087-9.

7 Tera H. Sedimentation of bile constituents. Ann Surg 1963; 157: 468-72.

8 Conrad MR, Janes JO, Dietchy J. Significance of low level echoes within the gallblader. Am J Roentgenol 1979; 132: 967-72.

9 Filly RA, Allen B, Minton MJ, Bernhoft R, Way LW. In vitro investigation of the origin of echoes within biliary sludge. J Clin Ultrasound 1980; 8: 193-200.

10 Glancy JJ, Goddard J, Pearson DE. In vitro demonstration of cholesterol crystals' high echogenicity relative to protein particles. J Clin Ultrasound 1980; 8: 27-9.

11 Bennion LJ, Grundy SM. Risk factors for the development of cholelithiasis in man. N Engl J Med 1978; 299: 1161-7, 1221-7.

12 Britten JS, Golding RH, Cooperberg PL. Sludge balls to gallstones. J Ultrasound Med 1984; 3: 81-2.

13 Holan KR, Holzbach T, Hermann RE, Coopermann AM, Claffey WJ. Nucleation time: a key factor in the pathogenesis of cholesterol gallstone disease. Gastroenterology 1979; 77: 611-7.

14 Holzbach T. Gallbladder statis: consequence of longterm parenteral hyperalimentation and risk factors for cholelithiasis. Gastroenterology 1983; 84: 1055-8.

15 Anderson JL. Acalculous cholecystitis - a possible complication of parenteral hyperalimentation. Med Ann DC 1972; 41: 448-50. 